\title{
Clinical outcomes using standard phacoemulsification and femtosecond laser-assisted surgery with toric intraocular lenses
}

This article was published in the following Dove Press journal:

Clinical Ophthalmology

30 March 2016

Number of times this article has been viewed

\author{
Arnaldo Espaillat' \\ Obniel Pérez' \\ Richard Potvin ${ }^{2}$ \\ 'Espaillat-Cabral Eye Institute, Santo \\ Domingo, Dominican Republic; \\ ${ }^{2}$ Science in Vision, Akron, NY, USA
}

Purpose: To compare the 1-month and 1-year results of toric intraocular lens (IOL) implantation with standard (manual) phacoemulsification vs femtosecond laser-assisted surgery.

Patients and methods: Refractive data, visual acuity data, and ocular aberration measured with a wavefront aberrometer were collected for two groups of patients from one site. The first group had standard phacoemulsification, while the second group had femtosecond laser-assisted surgery, and both groups were implanted with toric IOLs, either monofocal or multifocal. Differences in visual acuity, refractive outcomes, and higher order aberrations - total, corneal, and internal - were evaluated at 1 month and 1 year postoperatively.

Results: Toric IOLs were implanted in 62 eyes using standard phacoemulsification and 53 eyes using femtosecond laser-assisted surgery. Uncorrected visual acuity and best-spectacle-corrected visual acuity at 1 month and 1 year were not statistically significantly different between the groups $(P>0.05)$ nor was the mean cylinder or mean spherical equivalent refraction $(P>0.12)$. Total ocular higher order aberrations were significantly different between the groups $(P<0.05)$, but absolute differences appeared to be the same. Internal vertical coma was significantly lower in the femto group at 1 year $(P=0.03)$. Differences in aberrations did not correlate with corrected or uncorrected visual acuity.

Conclusion: Patients who underwent uncomplicated lens surgery with toric IOLs in both the groups had comparable refractive outcomes in terms of visual acuity and residual refraction at 1 year. The femto group had significantly lower internal vertical coma at 1 year.

Keywords: FLACS, LenSx, cataracts, refraction, astigmatism, visual acuity, toric IOL, femtosecond laser

\section{Introduction}

Approximately, a third of patients presenting for cataract surgery are likely to have clinically significant levels of corneal astigmatism. ${ }^{1}$ Toric intraocular lenses (IOLs) have been shown to be a safe and effective method of reducing astigmatism at the time of cataract surgery. ${ }^{2}$ However, after toric IOL implantation, residual astigmatism can still be problematic. Studies have reported residual astigmatism $>1.0 \mathrm{D}$ in $\sim 10 \%-12 \%$ of eyes and spherical equivalent refractive errors $>1.0 \mathrm{D}$ in $\sim 8 \%$ of eyes, with uncorrected visual acuity of $20 / 20$ in $41 \%-63 \%$ of eyes. ${ }^{2,3}$ The amount of residual astigmatism is unlikely to be related to IOL rotation since the majority $(93.3 \%)^{2}$ or all $^{3}$ of the IOL rotation was $\leq 10^{\circ}$, though surgically induced astigmatism (SIA) and IOL tilt were not evaluated as possible causes for this residual astigmatism. The expectations for emmetropia are high among patients receiving toric IOLs; optimizing refractive results after cataract surgery is especially important for these patients.
Correspondence: Richard Potvin Science in Vision, 6197 Dye Road, Akron, NY |400I, USA

$\mathrm{Tel}+\mathrm{I} 4076976008$

Fax + I 716 442 5110

Email rick@scienceinvision.com (c) (1) (\$) 2016 Espaillat et al. This work is published and licensed by Dove Medical Press Limited. The full terms of this license are available at https://www.dovepress.com/terms.php C. hereby accept the Terms. Non-commercial uses of the work are permitted without any further permission from Dove Medical Press Limited, provided the work is properly attributed. For permission for commercial use of this work, please see paragraphs 4.2 and 5 of our Terms (https://www.dovepress.com/terms.php). 
As a result, surgeons are interested in whether femtosecond laser-assisted cataract surgery (FLACS) offers any benefit over standard phacoemulsification with regard to reducing residual refractive error and improving uncorrected visual outcomes after toric IOL implantation.

FLACS has generated considerable interest, and debate, regarding its clinical advantages and disadvantages since its introduction several years ago. Femtosecond laser systems can be used to perform several steps in the cataract procedure: crystalline lens fragmentation, creation of the anterior lens capsulotomy, and corneal incisions. In general, safety and effectiveness of the laser cataract procedure have been shown to be similar to those of the standard cataract surgery though there may be an increased incidence of adverse events unique to using the laser, especially during the initial learning curve. ${ }^{4,5}$

It has been hypothesized that the increased accuracy in the corneal incision morphology may increase the predictability of the surgical outcome. ${ }^{6}$ Laser fragmentation may reduce phacoemulsification time and ultrasound energy, thereby reducing endothelial cell loss and rehabilitation time. ${ }^{7,8}$ It is also believed that precision in the capsulotomy centration, size, and shape may improve refractive stability and predictability by reducing the likelihood of IOL movement, tilt, and/or decentration. ${ }^{9,10}$ However, it remains unclear whether or not performing these steps with the laser translates to improvements in refractive outcomes over the current standard cataract surgery procedure. ${ }^{4,11}$

Several studies comparing FLACS with conventional cataract surgery found no difference in visual acuity, refraction, or corneal aberrations. ${ }^{4,6,12}$ Other studies have observed that more eyes had visual acuity better than 20/25 in the laser group compared to the standard group. ${ }^{12,13}$ The purpose of this retrospective study was to investigate the differences between higher order aberrations (HOAs), refraction, and visual acuity at 1 month and 1 year after cataract surgery in eyes implanted with a toric monofocal or multifocal lens where surgery was performed with or without the use of a femtosecond laser system.

\section{Patients and methods}

Local ethics approval for the data collection and analysis was requested and obtained from the Comité de Ética de la Investigación del Hospital General Plaza de la Salud. No patient protected data were collected or reported. A chart review for all eyes undergoing cataract surgery or refractive lens exchange with implantation of a toric IOL, monofocal or multifocal, between January 2012 and March 2014 was conducted. The choice of multifocal or monofocal IOL was based on patient preference, and use of the toric version of either IOL was based on preoperative corneal astigmatism. All implanted lenses were toric (monofocal or multifocal) one-piece lenses (AcrySof ${ }^{\circledR}$ SN6ATx or SND1TT; Alcon Laboratories, Inc., Fort Worth, TX, USA). Eyes with preoperative pathology (outside of cataract) and/or surgical complications were excluded. All surgeries were performed by the same surgeon (AE). The Holladay 2 formula was used for spherical power calculation and the AcrySof toric calculator for calculating cylinder power. Eyes with refractive data, visual acuity data, and ocular aberration measurements recorded at 1 month and 1 year postoperatively were tabulated. Visual acuity data were recorded in Snellen notation but converted to logarithm of the minimum angle of resolution (logMAR) for analytical purposes.

Eyes were categorized into one of two groups: group 1 (standard) included all eyes where surgery was completed with manual incisions and capsulorhexis with standard phacoemulsification, while group 2 (femto) included all eyes where a femtosecond laser system (LenSx; Alcon Laboratories, Inc.) was used to create the primary and secondary incisions, capsulotomy, and to perform initial lens fragmentation. In all the eyes, phacoemulsification was completed using the Centurion Vision System (Alcon Laboratories, Inc.). Eyes in which corneal arcuate incisions were performed were not included. Demographic data were also collected to determine if there were systematic differences between the groups.

Surgery in the standard group included a $2.2 \mathrm{~mm}$ singleplane primary incision on the temporal meridian with a $1.0 \mathrm{~mm}$ single-plane secondary incision. The manual capsulorhexis had a planned diameter of $5 \mathrm{~mm}$ and was centered on the dilated pupil.

Surgery in the femtosecond group involved using the laser with energy of $6 \mu \mathrm{J}$ for the corneal incisions. The primary incision was temporal and triplanar, with a trapezoidal configuration (2.3 mm internal size and $2.4 \mathrm{~mm}$ external size). Two secondary monoplanar $1.1 \mathrm{~mm}$ incisions were also made, each $60^{\circ}$ away from the primary; the second of these incisions was opened only in the case where bimanual irrigation/aspiration was required. A $5 \mathrm{~mm}$ capsulotomy centered on the dilated pupil was completed using energy of $7 \mu \mathrm{J}$.

An aberrometer (Nidek OPD Scan; Nidek Co Ltd., Gamagori, Japan) that uses time-based retinoscopy, also termed dynamic skiascopy, was used to measure the ocular aberrations of all eyes at 1 month and 1 year after surgery. The total, corneal, and internal aberrations of the eyes were measured using the manufacturer's instructions. These data were exported to a text file using the export function provided in the system software; aberrations were exported at a $5 \mathrm{~mm}$ diameter. 
The data exported from the aberrometer and extracted from patient charts were tabulated in an Excel spreadsheet; this spreadsheet was imported into an MS Access database for data checking, collation, and preliminary analysis (both from Microsoft Corporation, Redmond, WA, USA). Statistical analyses were performed using the STATISTICA data analysis software system, version 12 (StatSoft, Inc., Tulsa, OK, USA; www.statsoft.com). Statistical testing was performed using analysis of variance (ANOVA) on continuous variables and appropriate nonparametric tests on categorical data. Statistical significance was set at $P=0.05$.

\section{Results}

In the given time period, a total of 115 eyes were identified for inclusion, 62 eyes of 40 patients treated with standard phacoemulsification and 53 eyes of 41 patients treated using the femtosecond laser system. The ratio of bilateral eyes to unilateral eyes was not statistically significantly different between the groups ( $P=0.11$, Fisher's exact two-tailed test). Table 1 summarizes the data for the two groups. There was no statistically significant difference between the groups with regard to age, sex (Fisher's exact two-tailed test), axial length, or average keratometry. The eyes in the standard group had significantly more corneal astigmatism, but the difference was approximately $0.3 \mathrm{D}$ and considered clinically irrelevant. The ratio of multifocal toric IOLs to monofocal IOLs used was not statistically significantly different between the groups ( $P=0.3$, Fisher's exact two-tailed test $)$ nor was the average lens sphere power $(P=0.35)$. Only one patient had refractive lens exchange; hence, inclusion of these data was not deemed to be likely to materially affect the analysis.

Table 1 also includes the vector-calculated change in corneal astigmatism between the preoperative and 1-month visits, termed SIA. There was no statistically significant difference in SIA between the two groups $(P=0.95)$.
Figure 1 shows the results of ANOVA of the 1-month logMAR uncorrected distance visual acuity (UDVA) by IOL type, multifocal or monofocal. There was no statistically significant difference in UDVA by IOL type $(P=0.85)$. While the mean UDVA was about two letters better in the femto group, the difference was not statistically significant $(P>0.05)$. Results at 1 year (not shown) were different by one letter or less in all cases, which was again not statistically significant. Based on this, all subsequent analyses were performed with pooled data.

Figure 2 shows a box-whisker plot of the average UDVA of patients by group and time. There was no statistically significant difference between the two groups $(P=0.10)$ at either time point. There was a statistically significant effect of time $(P<0.01)$, with a loss of about one letter of UDVA between 1 month and 1 year; this change with time was not different between the groups and was clinically insignificant. The average UDVA for the standard and femto groups differed by less than two letters $(0.04 \log$ MAR $)$ at 1 month and less than one letter at 1 year postoperatively. The median UDVA at both time points for both the groups was between 0.0 and $0.1 \log$ MAR (20/20 to $20 / 25)$.

The mean best-spectacle-corrected distance visual acuity (CDVA) for the standard and femto groups at both the 1-month and 1-year time periods was within one letter $(0.02$ $\log$ MAR) of $0.0 \log$ MAR, the equivalent of $20 / 20$, with less than one-letter difference between all points. There was no statistically significant difference in CDVA by group or time ( $P>0.05$ in both the cases). Figure 3 shows a cumulative histogram of logMAR CDVA at 1 year.

The mean spherical equivalent refraction after surgery was not statistically significantly different between the groups at either 1 month (standard: $-0.09 \pm 0.40 \mathrm{D}$, femto: $-0.05 \pm 0.40 \mathrm{D} ; P=0.52$ ) or 1 year(standard: $-0.01 \pm 0.39 \mathrm{D}$, femto: $0.09 \pm 0.34 \mathrm{D} ; P=0.15)$. A higher percentage of eyes

Table I Eye data by group

\begin{tabular}{llll}
\hline Characteristics & Standard & Femto & $P$-value \\
\hline Number of eyes & 62 & 53 & $69.2 \pm 10.6(30,84)$ \\
Age (years) & $71.7 \pm 9.9(43,86)$ & $24 / 29$ & 0.20 \\
Sex (male/female) & $29 / 33$ & $20.7 \pm 3.8(11.5,27.0)$ & 1.00 \\
IOL sphere power (D) & $21.3 \pm 3.1(9.0,27.5)$ & $36 / 17$ & 0.35 \\
IOL type (single vision/multifocal) & $48 / 14$ & $23.52 \pm 1.18(21.46,27.06)$ & 0.30 \\
Axial length (mm) & $23.35 \pm 0.96(21.27,26.98)$ & $44.06 \pm 1.41(41.60,49.06)$ & 0.39 \\
Average K (D) $^{\mathrm{a}}$ & $44.09 \pm 1.32(41.05,47.68)$ & $1.29 \pm 0.55(0.54,3.67)$ & 0.88 \\
Corneal astigmatism (D) $^{\mathrm{a}}$ & $1.62 \pm 0.68(0.59,3.50)$ & $0.51 \pm 0.46$ & $0.01 *$ \\
Surgically induced astigmatism (D) $^{\mathrm{a}}$ & $0.50 \pm 0.35$ & 0.95 \\
\hline
\end{tabular}

Note: *Indicates statistically significantly different. ${ }^{a}$ Data presented as mean \pm SD (minimum, maximum). Abbreviations: IOL, intraocular lens; SD, standard deviation. 


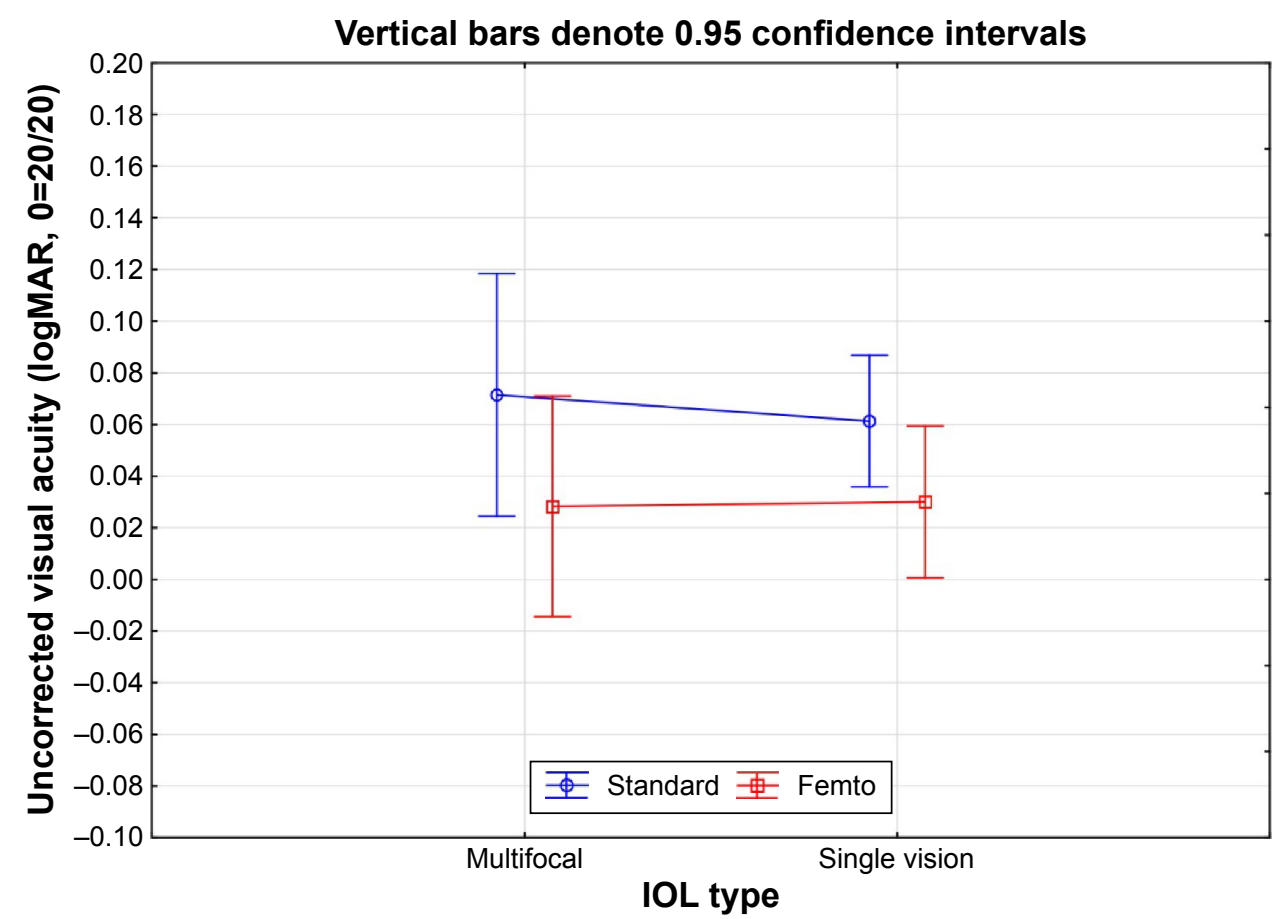

Figure I Uncorrected distance visual acuity at I month by IOL type and surgery group.

Abbreviations: IOL, intraocular lens; logMAR, logarithm of the minimum angle of resolution.

were within $0.5 \mathrm{D}$ of the intended target in the femto group compared to the standard group ( $50 / 53$ or $94 \%$ femto vs $53 / 62$ or $86 \%$ standard at 1 month and $48 / 53$ or $91 \%$ femto vs $52 / 62$ or $84 \%$ standard at 1 year). The differences in percentages were not statistically significantly different $(P=0.13$ at
1 month and $P=0.40$ at 1 year, Fisher's exact two-tailed test). Figure 4 shows a histogram of the spherical equivalent refraction results at 1 year for both the groups.

Average postoperative cylinder was also not statistically significantly different between the two groups at

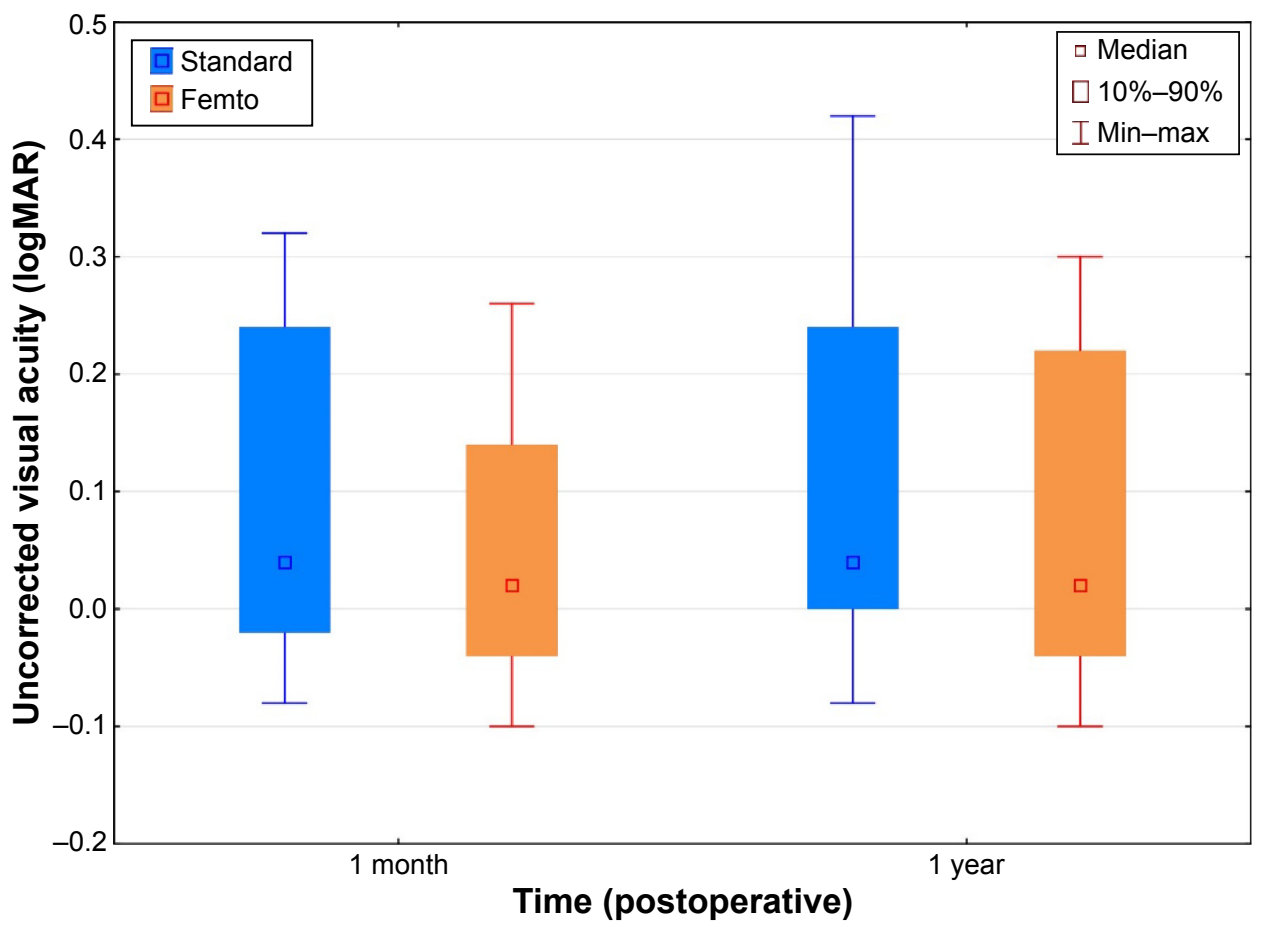

Figure 2 Uncorrected distance visual acuity by group and time.

Abbreviations: logMar, logarithm of the minimum angle of resolution; Min, minimum; Max, maximum. 


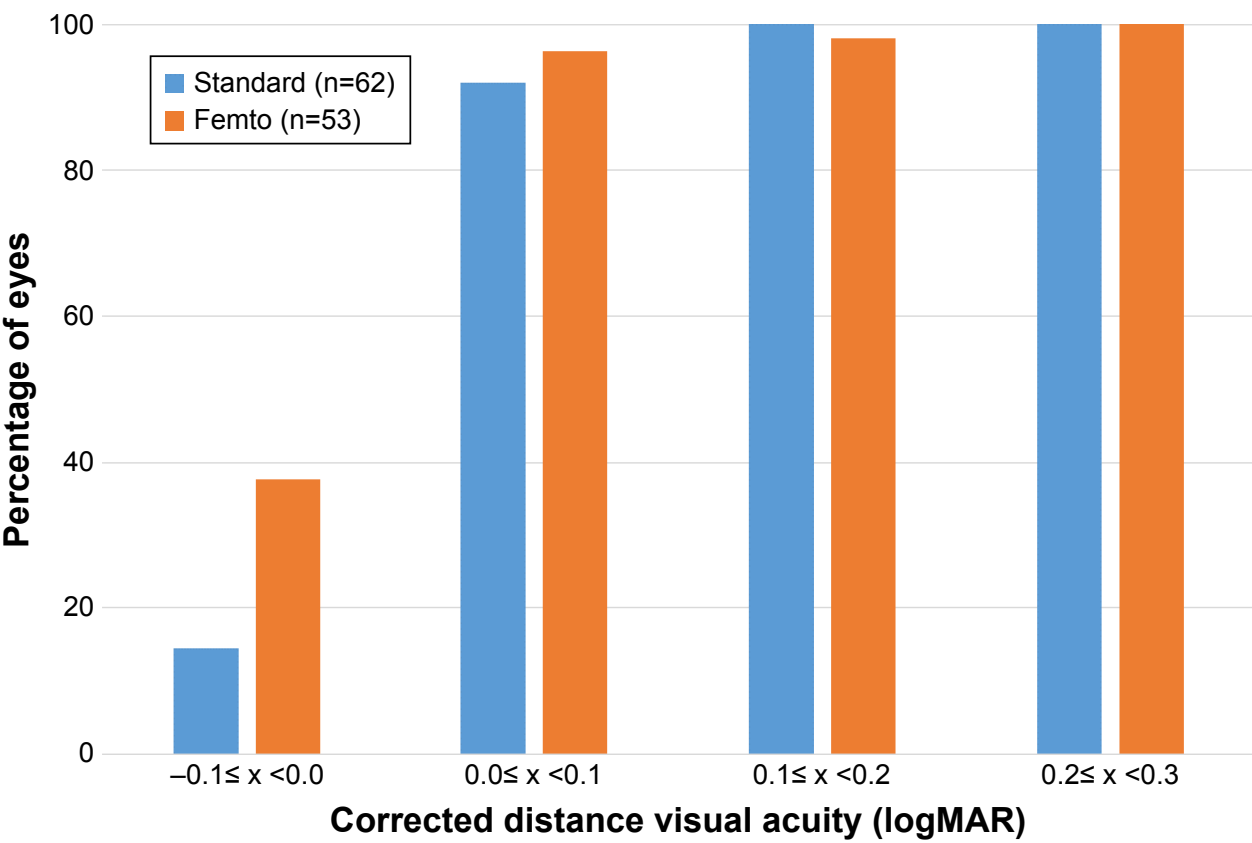

Figure 3 Cumulative distance-corrected visual acuity at I year by group. Abbreviation: logMAR, logarithm of the minimum angle of resolution.

either 1 month $(P=0.43)$ or 1 year $(P=0.12)$. There was a statistically significant increase in cylinder between 1 month and 1 year for both the groups $(P<0.01)$, but the average change was $<0.1 \mathrm{D}$ in both the cases, which was clinically insignificant. Only two eyes (one femto, one standard) had a measured cylinder change $>0.5 \mathrm{D}$ between 1 month and 1 year. The percentage of eyes with $\leq 0.50 \mathrm{D}$ of residual refractive cylinder was $85 \%(53 / 62)$ in the standard group and $98 \%(52 / 53)$ in the femto group at 1 month; this difference was statistically significantly different $(P=0.02$, Fisher's exact two-tailed test). At 1 year, the percentage of eyes with $\leq 0.50$ D of residual refractive cylinder was $69 \%(43 / 62)$ in the standard group and $83 \%(44 / 53)$ in the femto group; the difference in percentages at 1 year was

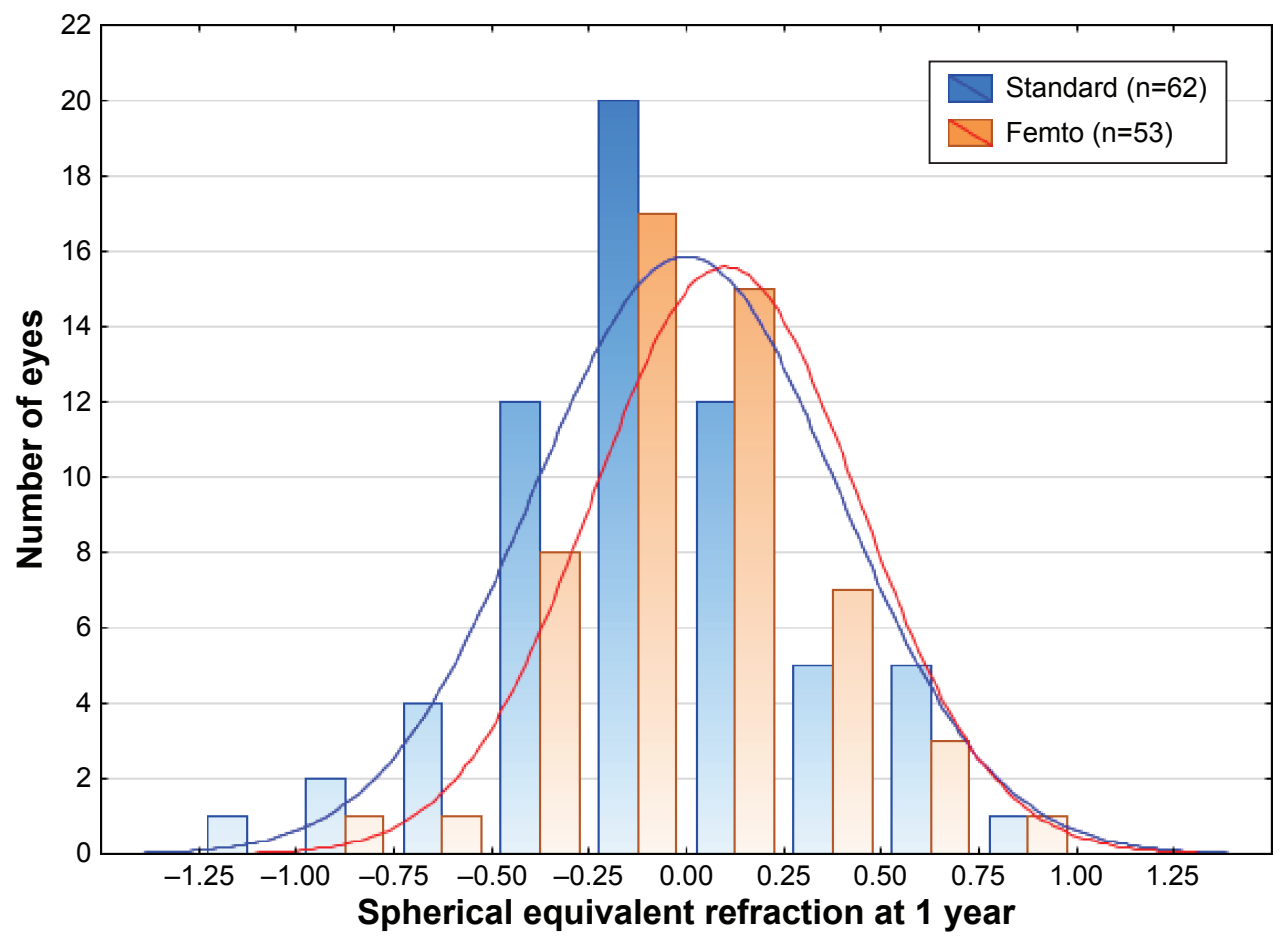

Figure 4 Spherical equivalent refraction at I year by group. 
Table 2 HOAs by type and time

\begin{tabular}{|c|c|c|c|c|}
\hline HOAs & $\begin{array}{l}\text { Time } \\
\text { postoperatively }\end{array}$ & $\begin{array}{l}\text { Standard } \\
(n=50 \text { at I month, } 40 \text { at I year) }\end{array}$ & $\begin{array}{l}\text { Femto } \\
\text { ( } n=48 \text { at I month, } 43 \text { at I year) }\end{array}$ & $P$-value \\
\hline \multirow[t]{2}{*}{ Ocular } & I month & $0.5 \mathrm{I} \pm 0.25(0.18, \mathrm{I} .2 \mathrm{I})$ & $0.44 \pm 0.26(0.16,1.28)$ & 0.23 \\
\hline & I year & $0.57 \pm 0.33(0.16,1.36)$ & $0.42 \pm 0.27(0.10,1.46)$ & $0.03 *$ \\
\hline \multirow[t]{2}{*}{ Corneal } & I month & $0.52 \pm 0.25(0.21,1.25)$ & $0.49 \pm 0.27(0.14,1.36)$ & 0.51 \\
\hline & I year & $0.54 \pm 0.30(0.18,1.37)$ & $0.43 \pm 0.25(0.16,1.57)$ & 0.07 \\
\hline \multirow[t]{2}{*}{ Internal } & I month & $0.54 \pm 0.46(0.15,2.87)$ & $0.5 \mathrm{I} \pm 0.36(0.17, \mathrm{I} .60)$ & 0.75 \\
\hline & I year & $0.60 \pm 0.45(0.17,2.08)$ & $0.50 \pm 0.4 \mathrm{I}(0.17,2.02)$ & 0.32 \\
\hline
\end{tabular}

Notes: *Indicates statistically significantly different; $n=$ number of eyes. Data is presented as mean \pm SD (minimum, maximum).

Abbreviation: HOAs, higher order aberrations; SD, standard deviation.

not statistically significantly different between the groups $(P=0.12$, Fisher's exact two-tailed test).

Table 2 summarizes the aberrometry measurements for the two groups. Aberrometry was measured successfully for 98 eyes at 1 month, with 83 eyes successfully measured at 1 year; of these, 67 eyes (30 standard, 37 femto) were measured at both time periods. The only statistically significant difference observed between the groups was for total ocular HOAs at 1 year. A repeated measures ANOVA showed no change in any of the HOA values over time $(P>0.10$ in all the cases). In addition, a correlation analysis showed no statistically significant correlations between any of the total HOA values (ocular, corneal, or interior) and UDVA or CDVA at either 1 month or 1 year postoperatively $(P>0.05$ in all the cases). There was also no difference in the measured aberrations by monofocal or multifocal lens type $(P>0.05$ in all the cases).

A specific examination of the Zernike coefficients related to tilt and coma was made. A repeated measures ANOVA showed no statistically significant difference in any of the tilt and coma values over time in either the standard or femto groups ( $P>0.08$ in all the cases). As a result, only the 1 -year data are shown here, as the longer follow-up period is presumably of greater interest. The effect of lens type (monofocal or multifocal) on the measured internal tilt and coma coefficients was also tested; there was no statistically significant difference by lens type ( $P>0.05$ in all the cases).

Table 3 presents the summary data for ocular, corneal, and interior tilt and coma values for each treatment group. There was a statistically significant difference in both vertical and horizontal tilt and coma for the total (ocular) aberrations $(P<0.05$ in all the cases). However, except in the case of horizontal coma, the differences in mean values appeared to be related to asymmetry, ie, the mean values were positive in one group and negative in another, but of the same magnitude. There were no statistically significant differences in the corneal aberrations ( $P>0.6$ in all the cases). A statistically significant difference was present for the internal vertical

Table 3 Ocular, corneal, and internal aberrations at I year

\begin{tabular}{|c|c|c|c|}
\hline \multirow[t]{2}{*}{ Parameter } & \multicolumn{2}{|c|}{ Mean \pm SD (minimum, maximum) } & \multirow[t]{2}{*}{$P$-value } \\
\hline & Standard $(n=40)$ & Femto $(n=43)$ & \\
\hline \multicolumn{4}{|l|}{ Ocular } \\
\hline Vertical tilt & $0.09 \pm 0.33(-0.58,0.95)$ & $-0.09 \pm 0.32(-1.33,0.43)$ & $0.01 *$ \\
\hline Horizontal tilt & $-0.07 \pm 0.31(-0.89,0.43)$ & $0.05 \pm 0.24(-0.53,0.57)$ & $0.05^{*}$ \\
\hline Vertical coma & $0.04 \pm 0.13(-0.23,0.31)$ & $-0.06 \pm 0.17(-0.85,0.15)$ & $<0.01 *$ \\
\hline Horizontal coma & $-0.07 \pm 0.15(-0.50,0.15)$ & $0.01 \pm 0.10(-0.26,0.24)$ & $<0.01 *$ \\
\hline \multicolumn{4}{|l|}{ Corneal } \\
\hline Vertical tilt & $-0.08 \pm 0.55(-1.38,1.34)$ & $-0.09 \pm 0.48(-0.88,1.30)$ & 0.95 \\
\hline Horizontal tilt & $-0.03 \pm 0.46(-1.02,0.96)$ & $0.0 \mathrm{I} \pm 0.37(-0.93,0.89)$ & 0.66 \\
\hline Vertical coma & $-0.08 \pm 0.20(-0.53,0.28)$ & $-0.06 \pm 0.20(-0.65,0.46)$ & 0.79 \\
\hline Horizontal coma & $0.00 \pm 0.15(-0.33,0.33)$ & $0.01 \pm 0.15(-0.43,0.39)$ & 0.83 \\
\hline \multicolumn{4}{|l|}{ Internal } \\
\hline Vertical tilt & $0.18 \pm 0.52(-1.29,2.03)$ & $0.00 \pm 0.52(-2.09,0.66)$ & 0.12 \\
\hline Horizontal tilt & $-0.05 \pm 0.46(-1.63,0.78)$ & $0.01 \pm 0.38(-0.93,1.04)$ & 0.51 \\
\hline Vertical coma & $0.12 \pm 0.21(-0.40,0.88)$ & $0.00 \pm 0.25(-1.09,0.54)$ & $0.03^{*}$ \\
\hline Horizontal coma & $-0.08 \pm 0.21(-0.87,0.22)$ & $-0.0 \mathrm{I} \pm 0.16(-0.47,0.32)$ & 0.11 \\
\hline
\end{tabular}

Notes: *Indicates statistically significantly different; $n=$ number of eyes.

Abbreviation: SD, standard deviation. 
coma values $(P=0.03)$, though not for internal vertical tilt values $(P=0.12)$. There were no statistically significant differences in internal horizontal tilt or coma.

A correlation analysis showed no statistically significant correlations between any of the tilt and coma values (ocular, corneal, or interior) and UDVA or CDVA at either 1 month or 1 year postoperatively ( $P>0.05$ in all the cases).

\section{Discussion}

The current study compared the visual acuity results, refractive outcomes, and measured aberrations between standard phacoemulsification and femtosecond laser-assisted cataract surgery in uncomplicated cataract surgery where eyes were implanted with a toric IOL. To our knowledge, this is the first study looking exclusively at toric IOL outcomes with FLACS.

The results show that UDVA and best-spectacle CDVA were not statistically or clinically significantly different between the femto and standard groups. This is in agreement with the literature suggesting that there is either no change or a very small difference between visual acuity results. ${ }^{6,9,12}$ The lack of difference may be due to the relatively small sample sizes. ${ }^{14}$ A larger study ${ }^{13}$ with 794 surgeries in a femto group and 420 surgeries in a standard group found that $12 \%$ more patients in the femto group had UDVA of 20/25 or better, though there was no difference between the groups in terms of the percentage of eyes with UDVA of 20/32 or better. The US Department of Veterans Affairs evaluated nine studies, three of which were randomized and controlled, comparing FLACS to standard phacoemulsification. They concluded that the evidence suggested CDVA was not significantly different between femtosecond-assisted and standard cataract surgery. ${ }^{4}$

In the current study, the mean spherical equivalent refraction was not significantly different between the two groups; this is in agreement with a previous large study, which found a difference in the mean spherical equivalent refraction of only $0.05 \mathrm{D}$ in favor of the femto group. ${ }^{13}$ The results of the current study show that, at the 1-year postoperative visit, $7 \%$ more patients in the femto group had spherical equivalent refractions within $0.5 \mathrm{D}$ when compared with the standard group. While not statistically significant, this appears consistent with a previous study which found $\sim 4 \%$ increase in the percentage of eyes within $0.5 \mathrm{D}$ in the femto group ( $\sim 69 \%)$ compared with the standard group $(\sim 65 \%)$. ${ }^{15}$ The same study found a higher mean absolute error in patients with short $(<22 \mathrm{~mm})$ and long $(>26 \mathrm{~mm})$ axial lengths when using the standard over the femto procedure. ${ }^{15}$ Another study reported a $0.02 \mathrm{D}$ difference in mean absolute refractive error in favor of the femto group compared with the standard group despite the presence of a learning curve in using the laser, and the use of a personalized A-constant in the standard group but not in the femto group. ${ }^{16}$ A more recent study by ConradHengerer et al shows that, at the 6-month postoperative visit, $21 \%$ more eyes in the femto group had refractions within $0.5 \mathrm{D}$ when compared with the standard group; this value is higher than that found in the current study. ${ }^{17}$ The difference in results may be due to the difference in population size, laser platform used, and the fact that the study of Conrad Hengerer et al used a monofocal spherical IOL, while we used toric monofocal and multifocal IOLs. ${ }^{17}$ Evidence suggests that the femtosecond laser systems may be associated with a lower absolute spherical equivalent refraction, but the differences relative to standard phacoemulsification may not always be clinically significant.

To our knowledge, no study has reported the residual refractive astigmatism after toric IOL implantation with laser cataract surgery. One study did demonstrate that SIA was not significantly different between the two groups. ${ }^{6}$ This is consistent with the results obtained in the present study.

In the present study, the percentage of eyes with residual refractive astigmatism of $\leq 0.50 \mathrm{D}$ was higher in the femto group at both 1 month and 1 year, though the difference was statistically significant only at 1 month; the sample size may be a limitation in this nonparametric analysis. A reduction in the number of eyes with residual refractive astigmatism of $\leq 0.5 \mathrm{D}$ over the course of 1 month to 1 year was evident in both the groups. This is likely a function of variability in performing the manifest refraction, as the measured mean cylinder for both the groups changed by $<0.1 \mathrm{D}$ in that time period and only two eyes (one femto, one standard) had an absolute change in refractive cylinder $>0.5 \mathrm{D}$ between 1 month and 1 year.

In the current study, the total ocular HOAs were significantly higher in the standard group at 1 year, though there was no difference in the total ocular, corneal, or internal HOAs at 1 month. This result is consistent with a previous study that found no significant difference between groups in terms of corneal HOAs after surgery. ${ }^{6} \mathrm{HOAs}$ were not correlated with visual acuity results at either time point; this is consistent with findings from a previous study. ${ }^{18}$

Looking specifically at tilt and coma aberration magnitudes at 1 year, all ocular mean values were statistically significantly different between the groups. This appeared to be a function of asymmetry in the mean values (ie, one plus, the other minus on average) rather than lower magnitudes 
in the femto group. However, internal vertical coma was statistically significantly lower in the femto group. This is consistent with the results observed in a previous study. In that study, the authors suggested that visual quality may be improved by lower IOL tilt, attributed to possibly lower magnitudes of corresponding coma in the laser group when compared to the standard group. ${ }^{18}$ While coma was lower in the femto group in the current study, actual IOL tilt was not measured. More sensitive measures of visual quality may be required to better elucidate the effects of IOL tilt and corresponding coma.

\section{Conclusion}

In conclusion, our study results demonstrate that in uncomplicated cataract surgery with toric IOL implantation, there were no clinically significant differences in visual acuity, spherical equivalent refraction, or residual refractive astigmatism between a group of eyes treated with standard phacoemulsification and a group treated with a femtosecond laser system at the 1-year postoperative time point. Total ocular HOAs at 1 year were slightly lower in the femtosecond laser group. Internal vertical coma was also significantly lower in the femto group. Further research is warranted to examine image quality and subjective visual improvements for patients in order to better establish the potential value of FLACS relative to standard phacoemulsification in this regard.

\section{Acknowledgments}

Espaillat-Cabral Eye Institute provided funding to Science in Vision to assist with data analysis and preparation of this manuscript. Sarah Y Makari, OD, a consultant to Science in Vision, received compensation for providing writing assistance to the authors in preparation of the manuscript.

\section{Disclosure}

The authors report no conflicts of interest in this work.

\section{References}

1. Hoffmann PC, Hütz WW. Analysis of biometry and prevalence data for corneal astigmatism in 23, 239 eyes. J Cataract Refract Surg. 2010; 36(9): 1479-1485.

2. Holland E, Lane S, Horn JD, Ernest P, Arleo R, Miller KM. The AcrySof toric intraocular lens in subjects with cataracts and corneal astigmatism: a randomized, subject-masked, parallel-group, 1-year study. Ophthalmology. 2010;117(11):2104-2111.
3. Ahmed II, Rocha G, Slomovic AR, et al; Canadian Toric Study Group. Visual function and patient experience after bilateral implantation of toric intraocular lenses. J Cataract Refract Surg. 2010;36(4):609-616.

4. Quiñones A, Gleitsmann K, Freeman M, et al. Benefits and harms of femtosecond laser assisted cataract surgery: a systematic review [Internet]. Washington (DC): Department of Veterans Affairs; 2013. Available from: http://www.ncbi.nlm.nih.gov/books/NBK185089/ PubMedPMID:24575450. Accessed July 17, 2015.

5. Abell RG, Darian-Smith E, Kan JB, et al. Femtosecond laser-assisted cataract surgery versus standard phacoemulsification cataract surgery: outcomes and safety in more than 4000 cases at a single center. $J$ Cataract Refract Surg. 2015;41:47-52.

6. Mastropasqua L, Toto L, Mastropasqua A, et al. Femtosecond laser versus manual clear corneal incision in cataract surgery. J Refract Surg. 2014;30(1):27-33.

7. Abell RG, Kerr NM, Vote BJ. Toward zero effective phacoemulsification time using femtosecond laser pretreatment. Ophthalmology. 2013;120(5):942-948.

8. Daya SM, Nanavaty MA, Espinosa-Lagana MM. Translenticular hydrodisection, lens fragmentation, and influence on ultrasound power in femtosecond laser-assisted cataract surgery and refractive lens exchange. J Cataract Refract Surg. 2014;40:37-43.

9. Toto L, Mastropasqua R, Mattei PA, et al. Postoperative IOL axial movements and refractive changes after femtosecond laser-assisted cataract surgery versus conventional phacoemulsification. J Refract Surg. 2015;31(8):524-530.

10. Kránitz K, Miháltz K, Sándor GL, Takacs A, Knorz MC, Nagy ZZ. Intraocular lens tilt and decentration measured by Scheimpflug camera following manual or femtosecond laser-created continuous circular capsulotomy. J Refract Surg. 2012;28(4):259-263.

11. Khandekar R, Behrens A, Al Towerki AE, et al. Determinants of visual outcomes in femtosecond laser assisted cataract surgery and phacoemulsification: a nested case control study. Middle East Afr J Ophthalmol. 2015;22(3):356-361.

12. Lawless M, Bali SJ, Hodge C, Roberts TV, Chan C, Sutton G. Outcomes of femtosecond laser cataract surgery with a diffractive multifocal intraocular lens. J Refract Surg. 2012;28(12):859-864.

13. Chee SP, Yang Y, Ti SE. Clinical outcomes in the first two years of femtosecond laser-assisted cataract surgery. Am J Ophthalmol. 2015;159(4): 714-719.

14. Palanker DV, Blumenkranz MS, Andersen D, et al. Femtosecond laserassisted cataract surgery with integrated optical coherence tomography. Sci Transl Med. 2010;2(58):58ra85.

15. Filkorn T, Kovács I, Takács A, Horváth E, Knorz MC, Nagy ZZ. Comparison of IOL power calculation and refractive outcome after laser refractive cataract surgery with a femtosecond laser versus conventional phacoemulsification. J Refract Surg. 2012;28(8):540-544.

16. Roberts TV, Lawless M, Chan CC, et al. Femtosecond laser cataract surgery: technology and clinical practice. Clin Experiment Ophthalmol. 2013;41(2):180-186.

17. Conrad-Hengerer I, Al Sheikh M, Hengerer FH, Schultz T, Dick HB. Comparison of visual recovery and refractive stability between femtosecond laser-assisted cataract surgery and standard phacoemulsification: six-month follow-up. J Cataract Refract Surg. 2015;41(7): $1356-1364$.

18. Miháltz K, Knorz MC, Alió JL, et al. Internal aberrations and optical quality after femtosecond laser anterior capsulotomy in cataract surgery. J Refract Surg. 2011;27(10):711-716. 
Clinical Ophthalmology

\section{Publish your work in this journal}

Clinical Ophthalmology is an international, peer-reviewed journal covering all subspecialties within ophthalmology. Key topics include: Optometry; Visual science; Pharmacology and drug therapy in eye diseases; Basic Sciences; Primary and Secondary eye care; Patien Safety and Quality of Care Improvements. This journal is indexed on

PubMed Central and CAS, and is the official journal of The Society of Clinical Ophthalmology (SCO). The manuscript management system is completely online and includes a very quick and fair peer-review system, which is all easy to use. Visit http://www.dovepress.com/ testimonials.php to read real quotes from published authors. 